\title{
Sindicalismo y tradiciones políticas de izquierda: un estudio cualitativo a partir de tres experiencias del sindicalismo de base en la Argentina durante el kirchnerismo
}

\author{
Syndicalism and left political traditions: a qualitative study based on three \\ experiences of rank and file unionism in Argentina during \\ the kirchnerism period.
}

\author{
Mariela Cambiasso* \\ Julieta Longo** \\ Juliana Tonani $^{* * *}$
}

\begin{abstract}
Resumen: En el artículo nos proponemos analizar comparativamente tres experiencias del denominado sindicalismo de base: Madygraf (ex Donnelley), Lear y el Subte (Subterráneo de Buenos Aires). Las tres estructuras laborales se encuentran ubicadas en el área Metropolitana de Buenos Aires (AMBA) de Argentina, en sectores que cuentan con una importante acumulación de experiencias de lucha y de organización en oposición a las direcciones oficialistas de sus sindicatos, que puede rastrarse desde las décadas de 1970 y 1980 . El objetivo que nos proponemos en el artículo es identificar los elementos en común y las heterogeneidades que pueden encontrarse entre estas organizaciones de base, en las cuales un sector de la dirección recupera la tradición política de izquierda. Algunas de las preguntas que orientan el trabajo son: ¿qué rasgos caracterizan a las experiencias de base que recuperan en la actualidad la tradición de izquierda?, ¿cuáles son sus similitudes?, ¿cuáles son sus diferencias?, ¿qué factores nos permiten explicar dichas diferencias? A partir de la comparación de los casos, en el artículo se sugiere que en cada uno de los lugares de trabajo analizados existen distintos modos de reapropiarse de la tradición de izquierda. Algunos elementos centrales para comprender dichas diferencias son: las particularidades que asumen las direcciones sindicales en cada sector, la política empresarial, la historia de lucha y de organización de los trabajadores, y el grado de consolidación de las direcciones opositoras. En términos metodológicos se trata de un estudio cualitativo, basado en la revisión de documentos sindicales y el análisis de entrevistas en profundidad realizadas entre los años 2013 y 2015 a delegados y activistas de las empresas bajo estudio.
\end{abstract}

\footnotetext{
* Argentina, Co-autora, Doctora en Ciencias Sociales (UBA), Becaria Posdoctoral del CONICET con lugar de trabajo en el CEIL. Docente de grado de la UBA. Mail: mcambiasso@ hotmail.com

** Argentina, Co-autora, Doctora en Ciencias Sociales (UBA), Becaria Posdoctoral del CONICET con lugar de trabajo en el CEIL. Docente de grado de la UNLP. Mail: longojulieta@gmail.com
} 
Mariela Cambiasso - Julieta Longo - Juliana Tonani, Sindicalismo y tradiciones políticas de izquierda: un estudio cualitativo a partir de tres experiencias del sindicalismo de base en la Argentina durante el kirchnerismo, Izquierdas, 36, noviembre 2017: 126-155

Palabras clave: Tradiciones políticas - izquierda - sindicalismo de base.

In the article we propose to analyze three experiences of the called rank and file unionism: Madygraf (ex-Donnelley), Lear and Subte (Subway of Buenos Aires). The three cases are located in the Metropolitan Area of Buenos Aires (AMBA) of Argentina, in sectors with important experiences of struggle and organization in opposition to the official's directions of their trade unions. The objective is to analyze the similarities and differences between different rank and file unionism experiences, in which a part of its directions recover the left political tradition. Some of the questions that guide the article are: what are the characteristics of these basis experiences? what elements do they have in common? what are their differences? and what factors we can allow to explain these differences? By the comparison between three cases, the article suggests that in each workplace there is a different way of reappropriating the left tradition. Some central elements to understand these differences are: the particularities of the trade union in each sector, the business policy, the history of the struggles and the organization of workers, and the degree of consolidation of these experience. The qualitative analysis is based on the analysis of trade union documents and interviews, performed between 2013 and 2015.

Key words: political traditions, left, rank and file unionism

Recibido: $14 / 03 / 2017$

Aceptado: 18/06/2017

\section{Introducción}

El proceso de surgimiento y recuperación de comisiones internas (CI) y cuerpos de delegados (CD) que comenzó a extenderse en Argentina a partir del inicio de los gobiernos kirchneristas (2003-2015) ${ }^{1}$ presentó características heterogéneas. Si bien hay consenso en los estudios académicos acerca del nuevo protagonismo que asumen las organizaciones sindicales $^{2}$ y la presencia de ciertos elementos de revitalización en las bases, la pregunta

\footnotetext{
${ }^{1}$ Bajo esta expresión se agrupa a los gobiernos de orientación peronista de Néstor Kirchner (2003-2007) y Cristina Fernández de Kirchner (2007-2015).

2 Al respecto pueden consultarse los trabajos de: Sebastián Etchemendy y Ruth Collier "Golpeados, pero de pie: Resurgimiento Sindical y Neocorporativismo Segmentado en Argentina (2003-2007)", en Politics and Society, vol. 35, n 3. Sage Publications, 2008, 363-401; Maurizio Atzeni y Pablo Ghigliani, Pablo "Nature and limits of trade unions mobilizations in contemporary Argentina", en Labour again publications. Amsterdam, International Institute of Social History, 2008; Palomino, Héctor "La instalación de un nuevo régimen de empleo en Argentina: De la precarización a la regulación", en Revista Latinoamericana de Estudios del Trabajo, año 13, nº 19, 2008, 121-144; y Cecilia Senén González y Julieta Haidar "Los debates acerca de la "revitalización sindical" y su aplicación en el análisis sectorial en Argentina", en Revista Latinoamericana de Estudios del Trabajo, 2 Época, n 22, 2009.
} 
Mariela Cambiasso - Julieta Longo - Juliana Tonani, Sindicalismo y tradiciones políticas de izquierda: un estudio cualitativo a partir de tres experiencias del sindicalismo de base en la Argentina durante el kirchnerismo, Izquierdas, 36, noviembre 2017: 126-155

por las orientaciones políticas que ha asumido este proceso se encuentra en buena medida abierta. Avanzar en este sentido es fundamental para debatir acerca de la dirección, los alcances y límites del denominado sindicalismo de base en Argentina ${ }^{3}$.

En un trabajo reciente distinguimos los rasgos de las tradiciones políticas presentes en organizaciones sindicales de base de la Zona Norte del Conurbano Bonaerense ${ }^{4}$. Allí señalamos que la tensión entre peronismo e izquierda sigue siendo actual para comprender las principales diferencias entre las tradiciones políticas recuperadas por las organizaciones sindicales: esta distinción forma parte del discurso de los entrevistados e interviene en sus disputas cotidianas. Pero si estas definiciones se establecían de modo claro en los discursos, cuando analizábamos las experiencias concretas la heterogeneidad era mucho mayor, y veíamos que de poco servían estas categorías preestablecidas. Luego de analizar los rasgos específicos de cada una de estas experiencias planteamos que no existía "izquierda" o "peronismo", sino combinaciones de rasgos de estas tradiciones políticas, que eran reapropiadas de modos diferenciales en los lugares de trabajo.

Partiendo de los avances previos, en este artículo nos proponemos analizar los elementos en común y las heterogeneidades que existen en las experiencias de CI y CD que recuperan la tradición de izquierda. Para ello, seleccionamos tres casos que comparten una serie de rasgos que hacen interesante su estudio. En primer lugar, en los tres casos un sector de las organizaciones de base se autodefine de izquierda y al menos un delegado milita en partidos políticos de izquierda. En segundo lugar, corresponden a tres sectores (gráfico, automotriz y tranviario automotor) que cuentan con una importante acumulación de experiencias de lucha y de organización en oposición a las direcciones oficialistas de sus sindicatos que puede rastrarse desde las décadas de 1970 y 1980. En tercer lugar, se trata de casos que pueden ser definidos como excepcionales en su tipo: (a) Madygraf (ex Donnelley) es una fábrica gráfica recientemente recuperada por sus trabajadores tras la quiebra de la firma en Argentina, (b) Lear es una fábrica de autopartes donde los trabajadores organizaron la única CI opositora a la dirección del SMATA entre 2009 y 2014, y (c) el Subterráneo de Buenos Aires, donde los trabajadores lograron construir un sindicato propio con reconocimiento institucional.

El artículo se estructura en cinco apartados. En el primero, planteamos brevemente el concepto de tradición del que partimos para avanzar en el análisis empírico de los casos. En el segundo, presentamos los rasgos compartidos por las tres experiencias analizadas. En el tercero, cuarto y quinto, analizamos los rasgos que asume la tradición política de izquierda

\footnotetext{
${ }^{3}$ Bajo esta expresión se agrupa, desde los primeros años del kirchnerismo, a las experiencias de CI y CD que se organizan en los lugares de trabajo y se definen en oposición a las direcciones sindicales burocráticas, reivindican la acción directa y las asambleas, y cuentan con la influencia de distintas corrientes políticas de izquierda. Ver: María Celia Cotarelo, "Movimiento sindical en argentina 2004-2007: ¿anarquía sindical?", XI Jornadas Interescuelas - San Miguel de Tucumán, Departamento de historia, Universidad Nacional de Tucumán, 2007; y Paula Varela, La disputa por la dignidad obrera. Sindicalismo de base fabril en la zona norte del Conurbano bonaerense 2003-2014. Buenos Aires, Imago MundiColección Archivos, 2015.

${ }^{4}$ Mariela Cambiasso, Julieta Longo, Juliana Tonani “¿Peronistas? ¿De izquierda? Tensiones en las tradiciones políticas en el sindicalismo de base en la actualidad", Paula Varela (coord.), El gigante fragmentado. Sindicatos, trabajadores y política durante el kirchnerismo, Buenos Aires, Final Abierto, 2016.
} 
Mariela Cambiasso - Julieta Longo - Juliana Tonani, Sindicalismo y tradiciones políticas de izquierda: un estudio cualitativo a partir de tres experiencias del sindicalismo de base en la Argentina durante el kirchnerismo, Izquierdas, 36, noviembre 2017: 126-155

en cada uno de los casos analizados, prestando especial atención a las heterogeneidades que las distinguen.

En términos metodológicos se trata de un estudio cualitativo, basado en entrevistas en profundidad a delegados y activistas, que realizamos entre los años 2013 y $2015^{5}$. Es importante señalar que, con el objetivo de poder analizar la complejidad de las experiencias y tener en cuenta distintas posiciones en cada una de ellas, en todos los casos de estudio entrevistamos tanto a delegados y activistas que militaban en distintos partidos políticos de izquierda, como a delegados y activistas que sólo militaban sindicalmente en sus lugares de trabajo. Asimismo, complementamos y contrastamos los discursos de los entrevistados con distintas fuentes secundarias (boletines, documentos, notas periodísticas, entre otras), a fines de profundizar la caracterización de los casos de estudio. El análisis de estos distintos documentos nos permitió no sólo reconstruir las prácticas sino también dar cuenta de los sentidos que cobran dichas prácticas. Ambos elementos, como veremos, son fundamentales para pensar las tradiciones políticas.

\section{La noción de tradición desde la escuela marxista inglesa}

Si bien el concepto de tradición fue poco abordado desde el marxismo, ha sido central en los estudios de la escuela marxista inglesa. En este sentido, se destacan los aportes de Edward P. Thompson, Eric Hobsbawm y Raymond Williams.

E. P. Thompson aborda el concepto de tradición examinando la relación entre las viejas tradiciones y las nuevas experiencias de los trabajadores. La diferencia entre ambas nociones no suele ser clara, y muchas veces el concepto de tradición se presenta en cierta forma subsumido al de experiencia, ya que es utilizado para dar cuenta de las experiencias acumuladas $^{6}$. A esto se suma que este concepto no ha sido tan abordado teóricamente como sí ocurrió con el de experiencia, lo que genera dificultades para precisar acabadamente esta noción en la obra del autor.

En la obra de E. Hobsbawm encontramos dos usos distintos del concepto. En su ensayo "Tradiciones obreras"” la definición se acerca más a la mirada general de Thompson, ya que refiere a las tradiciones como el resultado de la acumulación de ideas, teorías y tácticas. Pero en otras oportunidades, se enfoca en el modo en que las tradiciones son transformadas,

\footnotetext{
${ }^{5}$ El trabajo de campo se desarrolló en el marco de las siguientes investigaciones colectivas: Proyecto UBACyT (20132016): "Los trabajadores en la Argentina posdevaluación. Organización sindical en los establecimientos industriales del norte del Gran Buenos Aires"; y del Proyecto PIP-CONICET (2015-2017): "Los trabajadores en la Argentina actual Encuesta Obrera 10 años después-", ambos bajo la dirección de Paula Varela. Las entrevistas fueron realizadas junto con los estudiantes de los años 2013, 2014 y 2015 del Seminario de Investigación "Los trabajadores en la Argentina posdevaluación. Recomposición social y conflictividad sindical de 2003 en adelante”, de la Carrera de Sociología (Facultad de Ciencias Sociales, Universidad de Buenos Aires), a cargo de Paula Varela.

${ }^{6}$ Edwards P. Thompson. La formación de la clase obrera en Inglaterra. Barcelona: Editorial Crítica, 1989.

${ }^{7}$ Eric Hobsbawm. "Tradiciones obreras", en Gente poco corriente. Resistencia, rebelión y jazz. Barcelona: Planeta, 2013.
} 
Mariela Cambiasso - Julieta Longo - Juliana Tonani, Sindicalismo y tradiciones políticas de izquierda: un estudio cualitativo a partir de tres experiencias del sindicalismo de base en la Argentina durante el kirchnerismo, Izquierdas, 36, noviembre 2017: 126-155

utilizadas e incluso inventadas a partir de las necesidades del presente: así las tradiciones quedan definidas como los modos en que se legitiman y explican las acciones ${ }^{8}$.

Por su parte, en la obra de R. Williams la noción de tradición aparece directamente ligada al concepto de hegemonía. Allí la tradición es definida como un aspecto presente en todo proceso cultural, que actúa como un mecanismo de incorporación (selectiva) en el marco de la hegemonía, operando como un elemento formador del presente al desarrollar una versión del pasado, creada para establecer relaciones y ratificar los valores dominantes. Así, el eje principal de discusión se ubica en las disputas de poder e influencias que, en el caso de las sociedades de clases, se basa justamente en desigualdades entre las clases sociales $^{9}$. Al igual que Hobsbawm, en la conceptualización de Williams el eje está puesto en el proceso social activo de incorporación de prácticas y valores al orden social, aunque este último discute más abiertamente el problema de la tradición en términos de disputas de sentidos entre las clases sociales. Así, la tradición deja de ser entendida como un elemento conservador, es decir una herramienta de dominación que reproduce las relaciones de poder existentes, para dar lugar a una definición dialéctica. Es resultado y expresión de relaciones de fuerza, y en ella se cristalizan las experiencias de lucha acumuladas, que se resignifican en las actuales disputas de poder.

En base a los aportes de los autores mencionados, construimos una definición del concepto que nos permite pensar la recuperación de elementos históricos en las experiencias de organización sindical en los lugares de trabajo en la actualidad y también la reapropiación y disputas de sentidos en torno a dichos elementos. A diferencia de aquellos que se preguntaron por la tradición hegemónica a lo largo de la historia del movimiento obrero, optamos por utilizar el concepto en plural. Esto se debe a dos cuestiones principales. En primera instancia, a la particularidad de nuestro objeto de estudio, a saber, la organización sindical en los espacios de trabajo. En segundo lugar, y directamente ligado con lo anterior, porque nos preguntamos por la manera en que se expresan las disputas entre tradiciones en las organizaciones de base.

Teniendo en cuenta los elementos hasta aquí señalados, definimos a las tradiciones como procesos sociales activos (en oposición a cualquier intento de presentarlas como estructuras consolidadas o uniformes); que implican prácticas y concepciones acumuladas; pero que conllevan, a su vez, una reapropiación del pasado a partir de los intereses y las luchas del presente. Las tradiciones operan a nivel ideológico-cultural y se asientan institucionalmente (en partidos y corrientes políticas, organizaciones sindicales, movimientos, etc.); y son fundamentales tanto para la conformación de lazos sociales y grupos, como para legitimar sus prácticas. En el proceso activo de incorporación de prácticas y valores al orden social intervienen luchas de poder (entre clases y fracciones de clase) que es importante tener en cuenta para identificar las disputas e intereses en torno a ellas. Todo esto permite pensar la relación dialéctica entre las tradiciones y las nuevas experiencias o, dicho de otro modo,

\footnotetext{
${ }^{8}$ Eric Hobsbawm. "Introducción: la invención de la tradición”, en La invención de la tradición. Barcelona: Editorial Crítica, 2002.

${ }^{9}$ Raymond Williams. Marxismo y literatura. Barcelona: Editorial Península, 2000.
} 
Mariela Cambiasso - Julieta Longo - Juliana Tonani, Sindicalismo y tradiciones políticas de izquierda: un estudio cualitativo a partir de tres experiencias del sindicalismo de base en la Argentina durante el kirchnerismo, Izquierdas, 36, noviembre 2017: 126-155

entre lo acumulado y la necesidad de inventar para re-apropiarse del pasado, disputar los sentidos de la historia y legitimar las prácticas y estrategias del presente.

Así entendidas, las tradiciones políticas implican distintas visiones acerca de lo que deben ser y hacer las organizaciones sindicales en los espacios de trabajo, y la respuesta a ello se plantea estrechamente vinculada con la definición de los objetivos de las organizaciones, que incluye la manera en que se definen las oposiciones (adversarios) y las solidaridades en el espacio de trabajo.

Partiendo de esta definición, las tradiciones puedan ser asociadas con la noción de identidad ya que, tal como señala Stuart Hall, el concepto de identidad también es central para el análisis de la agencia y la política ${ }^{10}$. Las identidades, al igual que las tradiciones, son colectivas y se construyen en el marco de disputas, en las que se definen solidaridades (nosotros) y oposiciones (los otros). Sin embargo, sus diferencias son más importantes que sus puntos de contacto. Si las identidades están ancladas en los sujetos, las tradiciones lo están en instituciones u organizaciones. Si las identidades están en permanente cambio, por lo que distintos autores prefieren hablar de "identificaciones", las tradiciones también apelan a sentidos que se recuperan del pasado para presentar como legítima esa continuidad y defender determinadas prácticas en el presente. Por último, las tradiciones, involucran la definición de los objetivos que se proponen las organizaciones e instituciones.

Por último, si bien en Argentina no abundan los estudios que hayan recuperado teóricamente estas discusiones para el abordaje empírico de las organizaciones sindicales, sí existen investigaciones que reconstruyeron rasgos de las distintas tradiciones políticas del movimiento obrero a lo largo de la historia. Los debates entre distintas tradiciones políticas del movimiento obrero se concentran en particular en los estudios historiográficos de las décadas previas al peronismo (principalmente de los años ' 30 y ' 40$)^{11}$. Durante el peronismo, los debates se enfocaron en definir los rasgos de esta tradición política, y en señalar sus deudas con las tradiciones preexistentes en el movimiento obrero ${ }^{12}$. Recién en los estudios sobre los años de radicalización política del movimiento obrero a fines de los años ' 60 , comienzan a aparecer discusiones en torno a las tradiciones políticas recuperadas por las y los trabajadores. Concretamente, la discusión entre el peronismo y la izquierda, y su vínculo primero con la denominada resistencia y luego con el clasismo, será el centro de discusión de numerosos artículos ${ }^{13}$. Luego de la crisis de los estudios sindicales de los años

\footnotetext{
${ }^{10}$ Stuart Hall, “Introducción: ¿quién necesita identidad?”, Stuart Hall y Paul du Gay, Cuestiones de identidad cultural, Buenos aires-Madrid, Amorrortu Editores, 2003.

${ }^{11}$ Entre algunos de los trabajos que abordaron la temática pueden mencionarse los de Hernán Camarero, A la conquista de la clase obrera. Los comunistas y el mundo del trabajo en la Argentina, 1920-1935. Buenos Aires, Siglo XXI, 2007; y Diego Ceruso, La izquierda en la fábrica. La militancia obrera industrial en el lugar de trabajo, 1916-1943, Buenos Aires, Imago Mundi, 2015.

${ }^{12}$ Sólo para mencionar algunos ejemplos podemos citar los estudios de Alejandro Horowicz, Los cuatro peronismos, Buenos Aires, Planeta, 1991; Juan Carlos Torre, La vieja guardia sindical y Perón. Buenos Aires, Razón y Revolución, 2014; Daniel James, Resistencia e Integración. El peronismo y la clase trabajadora argentina, Buenos Aires, Siglo XX, 2006.

${ }^{13}$ Por ejemplo, pueden citarse los trabajos de Pablo Pozzi y Alejandro Schneider, Los setentistas. Izquierda y clase obrera. Buenos Aires, Eudeba, 2001; Alejandro Schneider, Los compañeros. Trabajadores, Izquierda y peronismo, 19551973, Buenos Aires, Imago Mundi, 2005; Héctor Löbbe, La guerrilla fabril. Clase Obrera e izquierda en la
} 
Mariela Cambiasso - Julieta Longo - Juliana Tonani, Sindicalismo y tradiciones políticas de izquierda: un estudio cualitativo a partir de tres experiencias del sindicalismo de base en la Argentina durante el kirchnerismo, Izquierdas, 36, noviembre 2017: 126-155

'90, a partir del año 2000 surgieron nuevas investigaciones que, en el marco de la discusión en torno a la existencia y rasgos del proceso de resurgimiento de los conflictos laborales, analizaron las tradiciones de lucha y de organización en determinados sectores y/o lugares de trabajo en la actualidad ${ }^{14}$. En el análisis que realizamos en este artículo recuperamos estos aportes no sólo para identificar las tradiciones presentes en el movimiento obrero argentino y sus rasgos principales, sino también para pensar modos de abordaje del problema.

\section{Tradiciones políticas de izquierda en las experiencias analizadas: algunos rasgos comunes}

Si bien las tres experiencias consideradas presentan rasgos singulares, no son menores entre ellas los puntos en común. A partir de estos rasgos compartidos podemos establecer que los activistas y delegados no sólo reivindican pertenecer a la tradición de izquierda, sino que esta reivindicación confiere características específicas a las organizaciones de base ${ }^{15}$.

En primer lugar, en los tres casos analizados los delegados y activistas señalan que la organización en el lugar de trabajo no es un fin en sí mismo sino un medio para organizar a los trabajadores y politizar el espacio de trabajo. Ello no significa que la organización no busque obtener mejoras inmediatas (aumentos salariales, reincorporación de despedidos, pase a planta de los tercerizados) que son necesarias e importantes para legitimar la organización, sino que el fin último de ésta se relaciona con la posibilidad de politizar los espacios fabriles. Por este motivo, los resultados de los conflictos (qué se obtiene) son casi tan importantes como el método a través del cual se logra (cómo se obtiene). La participación de los trabajadores, la disputa del control del proceso de trabajo, la posibilidad de re-subjetivizar la producción y el espacio laboral, son algunos de los objetivos que aparecen en el centro de estas organizaciones.

En segundo lugar, en estas experiencias las oposiciones se definen en términos de independencia política: de la empresa, del sindicato y, con matices, del Estado. La empresa en todos los casos analizados constituye un otro opuesto en intereses y, en algunos casos, llega a plantearse como un otro prescindible. Tal es el caso de Madygraf donde los

Coordinadora de Zona Norte del Gran Buenos Aires (1975-1976), Buenos Aires, Ediciones Razón y Revolución, 2006; y Ruth Werner y Facundo Aguirre, Insurgencia obrera en la Argentina 1969-1976. Clasismo, coordinadoras interfabriles y estrategias de la izquierda. Buenos Aires, Ediciones IPS, 2009.

${ }^{14}$ Julián Gindin, "La tradición sindical y la explicación de las prácticas sindicales. Conclusiones de una comparación internacional sobre los docentes del sector público". En: Revista Latino-americana de Estudos do Trabalho, Año 16, ${ }^{\circ}$ 26; Julieta Longo, ¿Renovación de las tradiciones sindicales en ámbitos laborales precarizados? Un análisis de las organizaciones sindicales en empresas supermercadistas durante la posconvertibilidad. Tesis doctoral. Universidad de Buenos Aires, 2014. Mariela Cambiasso "Organización sindical en el lugar de trabajo e izquierdas en la Argentina reciente: la Comisión Interna de Kraft-Mondelez (ex Terrabusi)”. En: Trabajo y Sociedad, no 26: Santiago del Estero, 2016.

${ }^{15}$ Los tres rasgos que mencionamos a continuación también fueron observados en otras siete experiencias que analizamos en un trabajo previo: Cambiasso op.cit. 
Mariela Cambiasso - Julieta Longo - Juliana Tonani, Sindicalismo y tradiciones políticas de izquierda: un estudio cualitativo a partir de tres experiencias del sindicalismo de base en la Argentina durante el kirchnerismo, Izquierdas, 36, noviembre 2017: 126-155

trabajadores retomaron la producción sin los empresarios. Una singularidad de estas experiencias es que también la dirección del sindicato aparece como un otro opuesto a los intereses de los trabajadores, que impide o dificulta su organización y las acciones que impulsan ${ }^{16}$. Finalmente, en relación con la posición frente al Estado, las diferencias son más marcadas. Más allá de los matices, que abordaremos en el próximo apartado, en los lugares de trabajo donde se recupera la tradición política de izquierda, la independencia en relación al Estado y/o al gobierno es un punto importante de discusión. Generalmente, el Estado es definido como garante de los intereses del capital, y esta definición se profundiza en el marco de conflictos abiertos con la empresa o con la dirección del sindicato, donde intervienen diversas instituciones de regulación o de represión.

En tercer lugar, la definición de las solidaridades en estos casos trasciende las fronteras de los espacios de trabajo y también del sector, configurando una suerte de nosotros ampliado, definido como "nosotros, los trabajadores"17. El cual, si bien no llega a definirse como clasismo, se opone claramente al corporativismo. Este punto es importante, ya que estas experiencias cuestionan uno de los elementos centrales de la constitución del sindicalismo argentino: la sindicalización por rama de actividad. Lo que delimita quiénes forman parte de este nosotros ampliado no es el sector, o la rama de actividad, sino la oposición a las direcciones sindicales, a sus métodos de decisión y acción, que son caracterizados como "burocráticos". En este sentido, la defensa de la democracia directa se presenta como un elemento central y las asambleas funcionan como un espacio privilegiado de debate de posiciones y toma de decisiones, presentándose como un antídoto contra la posible burocratización producto de la institucionalización. Las expresiones "delegado honesto", que "no se vende", y que "representa a los trabajadores", son constantes en las entrevistas a las y los delegados y activistas de estas CI y CD.

Sin embargo, más allá de estos elementos comunes, en el análisis empírico de los casos nos encontramos con diversos modos de apropiarse, significar y resignificar la tradición política de izquierda. En los aparatados que siguen analizaremos dichas heterogeneidades.

La tradición de izquierda ante la gestión obrera: el caso de Madygraf (ex Donnelley)

Donnelley es una empresa norteamericana de servicios de impresión, que se instaló en Argentina en 1992 al adquirir la editorial Atlántida Cochrane S.A. La planta está ubicada en el Parque Industrial Garín, en la zona norte del Gran Buenos Aires. Manuales escolares, folletos, libros y revistas como Para Ti, Gente, y Billiken son algunos de los productos que allí se imprimían.

\footnotetext{
${ }^{16}$ En el caso del Subte, como veremos más adelante, esta oposición derivó en la creación de un nuevo sindicato.

${ }^{17}$ Todas las palabras y expresiones que aparecen entrecomilladas son términos nativos, es decir, surgen de las palabras de las y los entrevistados.
} 
Mariela Cambiasso - Julieta Longo - Juliana Tonani, Sindicalismo y tradiciones políticas de izquierda: un estudio cualitativo a partir de tres experiencias del sindicalismo de base en la Argentina durante el kirchnerismo, Izquierdas, 36, noviembre 2017: 126-155

El 11 de agosto de 2014 la planta amaneció cerrada. Con un cartel en la puerta, la empresa comunicaba la quiebra de la firma en Argentina y el despido de sus 400 trabajadores. Como parte de una decisión votada en asamblea, los trabajadores y la CI, opositora a la dirección del sindicato, ingresaron a la planta y reiniciaron la producción. Rebautizada como Madygraf, la lucha por la expropiación de la planta y la estatización bajo gestión obrera abrió una nueva etapa en la historia de lucha y de organización de los trabajadores y la CI de la fábrica.

La experiencia de listas opositoras no era una novedad ni en el sindicato ni a nivel del lugar de trabajo. En los años '80 la Lista Naranja, opositora a la dirección del sindicato e influenciada por la izquierda partidaria ${ }^{18}$, dirigió la CI de la ex Atlántida. La oposición fue consolidándose en el lugar de trabajo sobre la base de mejoras concretas: la reducción de la jornada laboral de 8 a 6 horas, el fin de despidos a los activistas, y la firma de aumentos salariales por encima del convenio ${ }^{19}$. En los años `90 la CI debió enfrentar el cierre anunciado por la empresa. Luego de un extenso conflicto en el que los trabajadores tomaron la fábrica por más de 10 días, la empresa despidió a 390 trabajadores y a los delegados de la CI, luego de lo cual aumentó los ritmos de producción. Tras reabrir la fábrica, con un colectivo de trabajadores casi enteramente renovado por los despidos, se conformó una nueva CI afín a la dirección del sindicato:

... en el medio del conflicto de Atlántida [en los años '90] se instala una CI del sindicato de la Federación Gráfica Bonaerense, que está dirigida desde el '84 por Raimundo Ongaro, un dirigente de los '70, que fue secretario general de la CGT de los Argentinos, y tiene una tradición: luchó contra la dictadura de Onganía, peronista, luchó por la vuelta de Perón... Bueno, se instala una CI del sindicato, que básicamente no cambia ninguna realidad (Dirigente de Madygraf, militante partidario y sindical).

Algunos años después, en el marco de la crisis social, política y económica del año 2001 en Argentina, los trabajadores se enfrentaron a nuevos despidos. El conflicto fue nuevamente derrotado, en parte debido al contexto general en el que se produjo, y en parte por la prescindencia de la dirección del sindicato, a la que se sumó la renuncia de cinco de los siete delegados de la CI. A partir de entonces comenzó a gestarse un nuevo proceso de organización en la fábrica ligado, por un lado, al accionar de los dos delegados que no renunciaron $^{20} \mathrm{y}$, por otro lado, a la recomposición económica y del empleo de post-

\footnotetext{
${ }^{18}$ La Lista Naranja estaba conducida en ese momento por Néstor Pitrola, uno de los principales dirigentes del Partido Obrero (PO) en la actualidad.

${ }^{19}$ Emilio Martín, "Balance de la lucha de Atlántida”, En defensa del marxismo, núm. 17, julio, 2007.

${ }^{20}$ Uno de ellos en la actualidad es el principal dirigente de la fábrica. Al momento de iniciar su actividad gremial no militaba políticamente, luego comenzó a militar en el Partido de los Trabajadores Socialistas (PTS). El otro delegado actualmente es parte de la dirección del sindicato.
} 
Mariela Cambiasso - Julieta Longo - Juliana Tonani, Sindicalismo y tradiciones políticas de izquierda: un estudio cualitativo a partir de tres experiencias del sindicalismo de base en la Argentina durante el kirchnerismo, Izquierdas, 36, noviembre 2017: 126-155

convertibilidad, que influyó en la creación de nuevos puestos de trabajo y el ingreso de nuevos trabajadores a la planta ${ }^{21}$.

Sobre la base de un plantel de trabajadores renovado, en el año 2005 se desarrolló un conflicto en la fábrica que, habiéndose iniciado por demanda de aumento salarial terminó reclamando además la efectivización de los trabajadores contratados, y derivó en importante triunfo para los trabajadores.

Ese mismo año también hubo elecciones internas, y se eligió una CI completamente opositora a la dirección del sindicato. A partir de entonces no se registraron nuevos despidos, se efectivizaron a los trabajadores contratados, se firmaron paritarias más altas y se fue politizando el espacio de trabajo en base a la realización cotidiana de asambleas. Si se considera que las elecciones internas son nominales, la composición de la CI se transforma en un dato muy importante para medir el grado de representatividad de la oposición en la fábrica, que de 2005 en adelante hegemonizó todos los espacios de dirección a nivel del lugar de trabajo.

Sobre la base de esta breve caracterización de la historia de lucha y de organización de la CI de la fábrica, nos preguntamos qué tradición política de izquierda se recupera hoy en Madygraf.

Aunque actualmente la CI se plantea claramente como un medio de organización de los trabajadores, este objetivo no estaba definido desde el inicio, sino que se fue configurando conforme se consolidaba la nueva experiencia de oposición en la fábrica. El objetivo inmediato de defender los intereses de los trabajadores se fue ampliando hasta plantear la unidad entre efectivos y contratados, la articulación con otros sectores de trabajadores en lucha y el anti burocratismo, que definen la orientación actual de la CI.Si miramos la tradición política a partir de las oposiciones, observamos que un rasgo que define este caso es que la distinción con la empresa se plantea abiertamente en términos de clase. Como podemos observar en la siguiente cita:

Acá la patronal hacía torneos de fútbol. Nos explotaban todo el año y después teníamos que jugar un partido de futbol con ellos, o ir a la cena de fin de año. Entonces la CI ¿qué empezó a hacer? A organizarse, a reunirse afuera 'vamos a jugar a la pelota nosotros', 'vamos a hacer una fiesta de fin de año nosotros'. Y de a poco empezar a romper con diferentes maneras de estar acá adentro, que eran mínimas (...) Después, ya en el ambiente se notaba que había una diferencia de clase (Delegado de CI, Madygraf, militante partidario y sindical).

Esta posición, junto con el proceso de organización previo, permite explicar la casi inmediata resolución de reiniciar la producción bajo gestión obrera, tras la quiebra de la firma en el país. En ese momento la empresa fue definida rápidamente por los trabajadores

${ }^{21}$ Entre el primer trimestre del año 2003 y el cuarto trimestre del año 2005 se crearon 3,5 millones de puestos de trabajo (MTEySS, 2010). 
Mariela Cambiasso - Julieta Longo - Juliana Tonani, Sindicalismo y tradiciones políticas de izquierda: un estudio cualitativo a partir de tres experiencias del sindicalismo de base en la Argentina durante el kirchnerismo, Izquierdas, 36, noviembre 2017: 126-155

como un otro prescindible. Paralelamente, la ausencia de los representantes de la empresa contribuye a valorar positivamente la construcción de un espacio de trabajo organizado "entre compañeros":

Llegué, toqué el timbre y fue un compañero mío el que me abrió la puerta (...) Entrar y que otro compañero me pida que firme en un libro de actas a la entrada y cuando me vaya la salida, y ver a todos mis compañeros contentos, o sea, no había ningún jefe, ningún gerente (...) El entrar a trabajar y trabajar en las máquinas, producir, tener la fábrica bajo control obrero, con casi la totalidad de las máquinas produciendo es algo para mí inolvidable (Activista 1 de Madygraf, militante sindical).

Así, la perdurabilidad de la producción bajo gestión obrera va profundizando las diferencias entre la empresa y los trabajadores, y contribuye a reforzar las posiciones de clase. En este mismo sentido, a medida que se consolida la oposición en la fábrica, las diferencias con la dirección del sindicato se traducen en un proceso de organización independiente que pretende disputar la dirección gremial.

Sólo unos pocos días después de iniciada la producción bajo gestión obrera, un activista nos decía: "hoy en día la pelea ya no es sólo contra la patronal, sino que es contra el síndico $^{22}$, contra el gobierno, contra el Juez, y hasta con el sindicato" (Activista 1, militante sindical). Así como ocurre con la dirección del sindicato, la oposición frente al Estado también se profundiza con la toma de la fábrica. A partir de entonces, la lucha por la expropiación introduce un carácter permanente al enfrentamiento, hasta tanto no se resuelva.

Esta definición de los adversarios (empresa-sindicato-Estado), que se organiza reivindicando la independencia política, se combina con la configuración de solidaridades no sólo a nivel del lugar de trabajo, sino de la rama de actividad y de la clase obrera en su conjunto. En este caso, la discusión por la solidaridad aparece muy tempranamente ligada a la lucha por los contratados, que fue el puntapié inicial para comenzar a plantear una discusión más abierta sobre la importancia de la unidad de clase, donde la articulación con otros sectores de trabajadores, más allá de las fronteras de la fábrica, también comenzó a configurarse:

¿Por qué llegamos a dónde estamos? Porque se hizo todo un proceso de muchísimo tiempo. Se trabajaba acá, adentro de la fábrica, para mejorar las condiciones de trabajo, pero también se trabajaba afuera, que era lo que al principio nosotros no podíamos entender "¿Por qué se van afuera si los problemas los tenemos acá adentro?" Y ahí empezábamos con las discusiones. Discusiones fuertes ¿eh? Porque para que esto mejore no tiene que mejorar sólo acá en Donnelley, tiene que darse más ampliamente, hay que salir a la sociedad (Delegada de la Comisión de Riesgos del Trabajo, Madygraf, militante sindical).

\footnotetext{
${ }^{22}$ Es el encargado de liquidar el activo y el pasivo del deudor frente a un concurso de acreedores o una quiebra.
} 
Mariela Cambiasso - Julieta Longo - Juliana Tonani, Sindicalismo y tradiciones políticas de izquierda: un estudio cualitativo a partir de tres experiencias del sindicalismo de base en la Argentina durante el kirchnerismo, Izquierdas, 36, noviembre 2017: 126-155

Aunque, como puede observarse a partir de la cita, no se trató de un proceso lineal ni exento de contradicciones. Intervenir más allá de las fronteras de la fábrica era parte de la política de la CI opositora, y la posibilidad de instalarse entre los trabajadores involucró discusiones en asamblea, votaciones e importantes luchas políticas. Desde este punto de vista, el debate sobre la articulación con otros sectores de trabajadores contribuyó a politizar el espacio de trabajo, incorporando la posibilidad de discutir más allá de las demandas inmediatas y también más allá del espacio fabril.

Otro elemento que se presenta en las entrevistas es el lugar de la asamblea. La asamblea se plantea como el espacio de debate, que da lugar a las decisiones tomadas por las bases y, desde ese punto de vista, se vuelve central para la organización de los trabajadores. Además, se plantea como antídoto contra la propia institucionalización y el riesgo a la "burocratización", que tanto cuestionan a la dirección del sindicato. Pero en particular, en este caso también funciona como una instancia de politización del espacio de trabajo:

Una gran discusión dentro de la base es si vos discutís de los problemas internos y no hablas de política, o si discutís de todo. [En las asambleas] veníamos y hacíamos un pantallazo nacional: cómo estaba el gobierno, cómo estaba la economía, cómo estaban las distintas áreas, qué nos afectaba a nosotros como trabajadores de esa situación, y cuál era la mejor ubicación que podíamos tener nosotros en nuestra lucha. Partiendo de ahí, muchos compañeros lo veían bien y muchos compañeros decían: "esto no", "no se puede hablar en la asamblea de política". Y bueno, era la discusión, era convencerlo de que era necesario eso. Bueno hoy es totalmente natural, o sea se fue instalando con lucha política (Dirigente de Madygraf, militante partidario y sindical).

La política de la dirección de la CI de ampliar el temario para incorporar discusiones que trascienden las problemáticas sindicales particulares permite cuestionar la politización cerrada de la que habla Adolfo Gilly ${ }^{23}$, para referirse a las situaciones donde la política queda encerrada en el lugar de trabajo, operando sobre la división entre sindicalismo y política que atraviesa las relaciones entre los trabajadores (dentro y fuera de la fábrica). En este sentido, la lucha política de la CI por definir objetivos fundados en los principios de solidaridad de clase y las asambleas, se corresponde con la decisión de organizar a los trabajadores más allá de las demandas sindicales inmediatas, y de las fronteras que impone la fábrica. En este caso, el sindicato es un medio para conquistar demandas sindicales, pero, sobre todo, se plantea como un medio de politización del espacio de trabajo y de organización de la clase obrera en sí. La gestión obrera de la producción lleva al extremo el enfrentamiento abierto con la patronal, y define una experiencia de lucha que involucra el afuera de la fábrica:

${ }^{23}$ Adolfo Gilly, "La anomalía argentina (Estado, Corporaciones y trabajadores)", El estado en América Latina: teoría y práctica, México, DF, Siglo XXI, 2003. 
Mariela Cambiasso - Julieta Longo - Juliana Tonani, Sindicalismo y tradiciones políticas de izquierda: un estudio cualitativo a partir de tres experiencias del sindicalismo de base en la Argentina durante el kirchnerismo, Izquierdas, 36, noviembre 2017: 126-155

...como parte del proceso de organización, nosotros también levantamos la política de tener una relación con la comunidad y, por ejemplo, desde la organización de la fábrica estuvimos ayudando a todos los vecinos inundados de Las Tunas, juntamos alimentos, juntamos plata. Fuimos allá, los ayudamos. O sea, esa agrupación, que se organiza dentro de la fábrica, que quiere conquistar el gremio, y organiza otras fábricas, que se une con otros sectores del movimiento obrero y pelea junto con Kraft, con Lear, también, iba al barrio y trataba de aportar algún tipo de solución a los problemas que tiene la comunidad (Dirigente de Madygraf, militante partidario y sindical).

La posibilidad de trascender la frontera de la fábrica está dada por la decisión de reforzar los vínculos con otros sectores de la clase obrera, a partir de la idea de poner la fábrica "al servicio de la comunidad". Pero, a su vez, como argumentamos, esta discusión está directamente vinculada con la discusión sobre la independencia política y la lucha por la dirección del sindicato que mencionábamos más arriba.

Teniendo en cuanta lo dicho hasta acá, los rasgos que asume la tradición de izquierda en Madygraf se plantean a partir de la combinación de una serie de elementos específicos: una larga historia de lucha y de organización a nivel del lugar de trabajo; la estabilidad de más de diez años de una CI opositora a la dirección del sindicato; la presencia de tradiciones políticas de izquierda encarnadas en delegados y activistas que se volvieron militantes a partir de su trabajo en la fábrica; y el proceso de organización en el lugar de trabajo tras el quiebre de la firma norteamericana. Estos elementos, permiten explicar la radicalidad que asume el proceso general, encarnados en los objetivos que actualmente se da la CI, que se define como un medio de politización y de organización de la clase obrera en su conjunto.

\section{La debilidad de la izquierda en el SMATA: el caso de Lear}

Lear es una fábrica de autopartes, que se dedica a la producción de cableados de autos. $\mathrm{Su}$ principal cliente, la automotriz Ford, depende casi exclusivamente de su producción y de allí deriva su importancia estratégica: la interrupción del trabajo en Lear afecta directamente la producción en una de las terminales automotrices más importantes de Argentina.

En el mismo año en que los directivos de Madygraf se declararon en quiebra, se inició un conflicto que se prolongó durante seis meses en esta autopartista, ubicada a tan sólo seis kilómetros de la fábrica gráfica. La empresa despidió a 240 de sus trabajadores, impidió el ingreso de la CI opositora a la dirección del SMATA, e incumplió las resoluciones del Ministerio de Trabajo y los fallos de la justicia que ordenaban reincorporarlos, abriendo uno de los conflictos más importantes y visibilizados de la última década ${ }^{24}$.

\footnotetext{
${ }^{24}$ Lucila D'Urso y Julieta Longo, "Sindicalismo y política: el caso de la autopartista Lear como experiencia de sindicalismo radical en Argentina", $12^{\circ}$ Congreso Nacional de Estudios del Trabajo - ASET, Buenos Aires, 2015.
} 
Mariela Cambiasso - Julieta Longo - Juliana Tonani, Sindicalismo y tradiciones políticas de izquierda: un estudio cualitativo a partir de tres experiencias del sindicalismo de base en la Argentina durante el kirchnerismo, Izquierdas, 36, noviembre 2017: 126-155

Aunque la oposición de izquierda era una novedad en Lear, dado que desde su instalación en Argentina en los noventa su CI estuvo dirigida por el oficialismo del gremio, no lo era en el marco del sindicato metalmecánico en su conjunto. Distintos trabajos han abordado el protagonismo de los trabajadores del sector en el Cordobazo en el año 1969, el Viborazo en 1971 y la organización de las Coordinadoras Interfabriles en 1975, la experiencia de oposición en el SMATA Córdoba ${ }^{25}$, y la Lista Naranja ${ }^{26}$ que dirigió la toma de la fábrica Ford en el año $1985^{27}$. No obstante ello, desde aquel gran conflicto, la Lista Verde de orientación peronista, dirigió el sindicato sin la presencia de listas opositoras.

En este marco general, en el año 2005 empezó a desarrollarse en Lear una experiencia de organización de base opositora. El proceso fue paulatino. Los trabajadores comenzaron a organizarse clandestinamente, y muchas veces fuera de la planta, en partidos de fútbol y en reuniones sociales. En el año 2007 fue elegido por primera vez un delegado independiente, y en el 2009 resultaron electos tres. Como respuesta al avance de la oposición, en el año 2011 el SMATA cambió el sistema de votación. Por estatuto, las elecciones son nominales, pero ese año se planteó una elección por lista de candidatos. La oposición logró los avales y los cupos para conformar la Lista Celeste, que desplazó a todos los delegados oficialistas con el 55\% de los votos. La lista opositora estaba conformada por cuatro trabajadores independientes y un militante de izquierda. En las siguientes elecciones, en el año 2013, la dirección del SMATA llamó a votar nominalmente con la intención de conseguir al menos un delegado afín. Pese al cambio en el sistema de votación, la Lista Celeste ganó con el $70 \%$ de los votos, y conservó los cinco delegados. La lista Celeste, en ese momento, estaba conformada por delegados y activistas que se reivindicaban independientes, otros que se autodefinían como kirchneristas, y otros vinculados con partidos políticos de la izquierda trotskista ${ }^{28}$. En este contexto nos preguntamos iqué izquierda estaba presente en Lear?

La decisión de organizarse en oposición a la dirección del SMATA en esta fábrica se planteó inicialmente con el objetivo de democratizar el gremio y "defender los derechos de los trabajadores". Sin embargo, algunos elementos propios del sector, junto con la presencia de militantes de izquierda, en un contexto de ascenso de las expectativas de los trabajadores ${ }^{29}$ hicieron que este objetivo se radicalizara y se politizara la manera en que los

\footnotetext{
25 Esta experiencia fue liderada por René Salamanca del Partido Comunista Revolucionario (PCR), de orientación maoísta.

${ }^{26}$ En esta experiencia tuvieron influencia el PCR, el PO y el Movimiento al Socialismo (MAS).

${ }^{27} \mathrm{Al}$ respecto pueden consultarse los trabajos de Nuria Giniger, Sebastián Guevara, Marcelo Hernández y Cynthia Rivero, "Las huellas del terrorismo de estado sobre el movimiento obrero. Los casos de Ford y Acindar". En: Claudia Figari, Paula Lenguita y Juan Montes Cató, El movimiento obrero en disputa, Buenos Aires, Editial CICUS, 2010; Leandro, Molinaro, "La democracia del Nunca más y el movimiento obrero. La ocupación obrera de la planta Ford de General Pacheco en 1985”, en Revista Archivos de Historia del Movimiento Obrero y la Izquierda n², Buenos Aires, 2013; y Rodolfo Laufer, "El clasismo en el SMATA Córdoba. Ocupaciones fabriles, democracia sindical e izquierda clasista: la toma de la matricería Perdriel, mayo de 1970". En Estudios del Trabajo, vol. 49, 2015.

${ }^{28}$ Algunos miembros de la Lista Celeste militaban en el PTS. Durante el transcurso del conflicto uno de los delegados independientes comienza a vincularse con el PO. Estos dos partidos son los que influyen principalmente durante el conflicto de 2014.

${ }^{29}$ Paula Varela, op. cit.
} 
Mariela Cambiasso - Julieta Longo - Juliana Tonani, Sindicalismo y tradiciones políticas de izquierda: un estudio cualitativo a partir de tres experiencias del sindicalismo de base en la Argentina durante el kirchnerismo, Izquierdas, 36, noviembre 2017: 126-155

trabajadores y delegados definían las oposiciones y construían solidaridades en el espacio de trabajo.

En Lear, cuando los activistas y delegados hablan de nosotros se refieren a la posibilidad de reconstituir la unidad entre los distintos sectores y categorías de trabajadores de la planta. Nosotros, significa ser "compañeros". Este elemento, por ejemplo, se explicita en la elección del nombre de la lista opositora:

Pregunta: ¿Por qué le ponen Lista Celeste?

Activista: Por la ropa de laburo. Fuimos al SMATA, nos presentamos: "nos venimos a presentar como candidatos". Y nos dijeron: "bueno, esto es por lista, somos la Lista Verde, ustedes ¿qué lista son?”. E hicimos así, nos miramos la ropa: remeras celestes. Entonces bueno, somos La Celeste. Activista: Y también para que se identifique la gente, ¿no?

Delegado: Con la ropa de laburo, sí.

Activista: Con sus compañeros. (Entrevista a Activista 1 y Delegado 1 de CI, Lear, ambos militantes partidarios y sindicales).

El "nosotros, compañeros de la fábrica", es el elemento principal a partir del cual se legitima la organización sindical opositora. En un principio, busca disolver las diferencias a través de las cuales las políticas empresariales dividen a los trabajadores entre efectivos y contratados o entre trabajadores del turno mañana y del turno tarde. Reconocerse como "compañeros" es uno de los primeros objetivos que se propone la organización colectiva opositora, incluso antes de dirigir la CI:

Delegado: ... [Uno de los primeros activistas de la fábrica] siempre organizaba torneos de fútbol en el turno noche. Acá a la vuelta hay una cancha que se llama "Campo Nuevo". Son tres o cuatro canchas. Y [nombre del activista] las llenaba.

Pregunta: Y así, con reuniones más sociales, ¿empezaron a poder discutir? Delegado: Sí, así uno se iba conociendo y se iba integrando y te enterabas de lo que pasaba en otro sector, porque eso en la fábrica no lo podés hacer. Entonces te vas conociendo y relacionando así, en un ámbito más social, con un montón de compañeros (Delegado 1 de CI, Lear, militante partidario y sindical).

Al igual que en otras experiencias que recuperan una tradición de izquierda, en Lear la solidaridad no sólo se construye en la planta, sino que se extiende hacia otras fábricas de la zona. Esto ocurre en momentos específicos, sobre todo en el marco de conflictos abiertos. En estos casos el eje de la solidaridad se construye a partir de las condiciones de trabajo, es decir, de compartir las mismas experiencias de explotación:

Si bien nosotros arrancamos toda esta organización para pelear por mejores condiciones de trabajo, con el correr de los años nos fuimos juntando con chicos de otras fábricas, que te cuentan su realidad y parece que fuese un compañero tuyo. Muchas empresas, muchos lugares 
Mariela Cambiasso - Julieta Longo - Juliana Tonani, Sindicalismo y tradiciones políticas de izquierda: un estudio cualitativo a partir de tres experiencias del sindicalismo de base en la Argentina durante el kirchnerismo, Izquierdas, 36, noviembre 2017: 126-155

diferentes, donde están viviendo la misma realidad... (Delegado 2 de CI, Lear, militante sindical)

Concretamente, la solidaridad se planteó en principio con trabajadores de otras plantas autopartistas que también tenían algunos delegados opositores en sus CI (particularmente Gestamp y Dana), luego se extendió a otras fábricas de la zona (por ejemplo, Madygraf). Pero, a diferencia de la solidaridad que se construye en el lugar de trabajo, la solidaridad con trabajadores de otras fábricas y con otros sectores de la clase obrera no está tan extendida como vimos en Madygraf, sino que permanece ligada al accionar de los delegados y activistas.

La legitimación de la organización de base opositora se explica también por la ausencia de respuestas de los dirigentes sindicales oficialistas frente a las demandas de los trabajadores:

Lo que te dicen ellos [el sindicato] es el típico discurso de la burocracia y del carnero, ¿no? Cuál es: "Bueno, si no te gusta [este trabajo], si explotan, ¡buscate otro!". No le quieren explicar a la gente que tenés derechos, y que la empresa tiene que respetar tus derechos. Entonces ellos encaran por el otro lado. Te quieren hacer creer que uno es un fracasado porque uno no va a buscar otro laburo, no... el fracasado es ese que no se anima a luchar por los derechos que tiene (Activista 2, Lear, militante sindical).

Así, el accionar del sindicato en el sector automotriz conlleva a una apropiación particular de la tradición de izquierda, principalmente en relación a la manera en que se plantea la independencia política del sindicato y, a través de él, del gobierno. La dirección del SMATA actúa disciplinando a la oposición en el sector a través de distintos mecanismos, que incluyen la formación de dirigentes y delegados, pero también la supresión de la oposición en casos como Lear donde llega a dirigir la $\mathrm{CI}^{30}$. Frente a este accionar, los activistas y delegados de la fábrica opositores no sólo cuestionan los métodos del SMATA, al caracterizarlos de "burocráticos", sino su posicionamiento contra los trabajadores $^{31}$. Tal es así que, en el marco del conflicto, la dirigencia sindical fue denunciada por coordinar acciones con la empresa en contra de los trabajadores, e incluso, fue señalada en algunos momentos, como el adversario principal de los trabajadores:

El trabajador se está dando cuenta ahora que no solo te persigue la empresa, el supervisor, sino que también te persigue el sindicato (...) el sindicato es una herramienta más de la empresa... (Activista 2, Lear, militante sindical).

\footnotetext{
${ }^{30}$ Paula Varela y Débora Vasallo, "El disciplinamiento en la producción: la estrategia del SMATA en los lugares de trabajo, Paula Varela (coord.), El gigante fragmentado. Sindicatos, trabajadores y política durante el kirchnerismo, Buenos Aires, Final Abierto.

${ }^{31}$ D'Urso y Longo, op cit.
} 
Mariela Cambiasso - Julieta Longo - Juliana Tonani, Sindicalismo y tradiciones políticas de izquierda: un estudio cualitativo a partir de tres experiencias del sindicalismo de base en la Argentina durante el kirchnerismo, Izquierdas, 36, noviembre 2017: 126-155

El Estado también se construyó como un otro opuesto durante el desarrollo del conflicto de 2014, en el que intervino a través del Ministerio de Trabajo, por un lado, y a través de la Gendarmería Nacional y la Policía Federal y Bonaerense, por otro:

... Nos enteramos que el SMATA viene teniendo estas audiencias con la empresa en el Ministerio [de Trabajo] a espaldas de los delegados y los trabajadores, cuando nosotros los hemos notificado ante cada ataque de la empresa (Comunicado de la Comisión Interna de Lear, 15 de julio 2014).

... denunciamos que es el propio gobierno el que le brinda a Lear un enorme dispositivo de gendarmes y de policías, que fue el gobierno el que les permitió realizar medidas ilegales como los despidos masivos sin declarar preventivo de crisis, luego el lockout, y permite al día de hoy la importación de cables desde el exterior (Comunicado de la CI, 14 de octubre 2014).

Así, en el discurso de los delegados y activistas opositores la crítica al gobierno se plantea directamente articulada con el cuestionamiento al accionar de la dirección del sindicato y de la empresa.

Considerando lo expuesto, sostenemos que la tradición de izquierda que se recupera en Lear se define a partir de la combinación de una serie de elementos particulares. En primer lugar, la existencia de una política patronal, que aumenta los ritmos de trabajo y "rompe" a los trabajadores. En segundo lugar, el accionar de un sindicato que se transforma, incluso, en un adversario más opuesto a los trabajadores que la propia empresa. Y, en tercer lugar, por la presencia de activistas y delegados de izquierda que promueven la organización interna, reivindicando la tradición de izquierda en la fábrica.

Esta combinación se expresa en ambivalencias en relación a los objetivos de la CI. La organización de base independiente, en principio, es necesaria para defender los derechos de "los compañeros de trabajo". Pero, por la radicalidad del accionar de la empresa y por la ausencia de defensa de estos derechos por parte de la dirección del sindicato, este objetivo se politiza y asume rasgos combativos y de izquierda. En principio porque defender los derechos de los trabajadores y cuestionar los ritmos de trabajo implica, en este caso necesariamente, enfrentar la estrategia de la dirección sindical y cuestionar la desmoralización que impone a los trabajadores:

[En la fábrica] siempre echaban gente y no pasaba nada. Pero por eso te digo, a partir de un momento, del 2008 por lo menos, para mí fue donde yo hice click. Y donde bueno, yo me meto [a militar], porque si no me meto yo no lo va a hacer nadie (...) ¿Qué me convenció a mí? Y eso, lo que te decía, ver que los trabajadores estábamos solos. La patronal ya sabíamos que... olvidate. Y el sindicato, en los momentos de paz está todo bien, y echan a uno y te dicen "está todo bien, no pasa nada, es vago", y no pasa nada. (Delegado 1 de CI, Lear, militante partidario y sindical). 
Mariela Cambiasso - Julieta Longo - Juliana Tonani, Sindicalismo y tradiciones políticas de izquierda: un estudio cualitativo a partir de tres experiencias del sindicalismo de base en la Argentina durante el kirchnerismo, Izquierdas, 36, noviembre 2017: 126-155

Tal como se desprende de la cita, en Lear la recuperación de una tradición de izquierda se plantea casi como la única opción para enfrentar al despotismo patronal y al accionar del sindicato. La configuración del nosotros asume rasgos de independencia frente a la ausencia de cualquier política de conciliación por parte de la dirección del sindicato. El objetivo de mejorar las condiciones de trabajo se transforma así en una demanda que politiza el espacio de trabajo. Sin embargo, la radicalidad del ataque de la empresa, en sintonía con la dirección del sindicato termina configurándola como una experiencia de oposición débil que, tras dos mandatos consecutivos, es derrotada en 2014.

\section{¿La izquierda institucionalizada? El caso del Subte}

En 1994, en el marco de las privatizaciones impulsadas por el Estado, se dio el traspaso del servicio del Subte a la empresa Metrovías S.A. La privatización implicó, entre otras cosas, una fuerte reducción del plantel de trabajadores, a través de despidos y retiros voluntarios; y la tercerización de varias de las actividades que anteriormente estaban concentradas en el sector. Esta decisión, no se fundaba sólo en razones económicas. La inclusión de jóvenes, junto con las nuevas modalidades de contratación precarias, daba por resultado un plantel de trabajadores fragmentados y sin experiencia previa de organización ${ }^{32}$. Sin embargo, sin contar en sus espaldas con el peso de las derrotas de las luchas pasadas, pero siendo quienes sufrían en mayor medida las nuevas (y peores) condiciones de trabajo, de estos jóvenes surgiría el nuevo CD del Subterráneo que comenzó a organizarse desde mediados de los años noventa. A partir del encuentro entre un núcleo de militantes de organizaciones de izquierda y de jóvenes con experiencias de militancia social (en centros de estudiantes, organizaciones barriales, cooperativas, etc.), empezó a gestarse lo que luego se conoció como "Metrodelegados", para hacer referencia a la organización de delegados opositores a la dirección de la Unión de Tranviarios Automotor $(\mathrm{UTA})^{33}$.

La experiencia de oposición a la UTA no es una novedad en el Subte. En 1975, en el marco de un proceso generalizado de ascenso obrero en Argentina, sus trabajadores votaron el primer CD íntegramente opositor. En los meses siguientes, pusieron en pie la Coordinadora Interlíneas, donde confluyeron delegados de las 5 líneas de subterráneos y sus talleres, así como también delegados de choferes de colectivos. La dictadura de 1976 logró desarticular esta experiencia, pero hacia fines del gobierno de facto comenzaron los

\footnotetext{
32 Paula, Abal Medina, Cora Arias, Karina Crivelli y Nicolás Diana Menéndez, "Las configuraciones del conflicto laboral en empresas de servicios. Un estudio de casos en call centers y subtes", e-l@tina, Revista electrónica de estudios latinoamericanos, Vol. 6, n²3, abril-junio, Universidad de Buenos Aires, Facultad de Ciencias Sociales, 2008.

33 Entre las principales agrupaciones que se conformaron a partir de este encuentro se destacan Los Topos, bajo la influencia del MAS; Trabajadores de Metrovías, bajo la influencia del PO; y El Túnel, que aglutinaba a ex militantes de partidos tradicionales de izquierda y a militantes con experiencia social. Entre sus integrantes se destaca "Beto" Pianelli, que en la actualidad forma parte de la Secretaría Ejecutiva de AGTSyP. Ver: Patricia Ventrici, Federico, Vocos y Manuel Compáñez, Metrodelegados. Subte, de la privatización al traspaso, Buenos Aires, Editorial Desde el Subte, 2012.
} 
Mariela Cambiasso - Julieta Longo - Juliana Tonani, Sindicalismo y tradiciones políticas de izquierda: un estudio cualitativo a partir de tres experiencias del sindicalismo de base en la Argentina durante el kirchnerismo, Izquierdas, 36, noviembre 2017: 126-155

primeros intentos de reorganizar el lugar de trabajo en torno al reclamo por las 6 horas de trabajo ${ }^{34}$.

De este modo, la experiencia de oposición de los "Metrodelegados" cuenta con antecedentes previos, donde la izquierda tuvo un peso importante. Así como en los años setenta, en esta nueva etapa la organización surgió nuevamente de forma clandestina, y desde sus comienzos el objetivo fue disputar la estructura del CD, que hasta ese momento estaba hegemonizado por delegados afines a la dirección de la UTA. Este proceso comenzó con la elección de un delegado opositor en 1996. En el 2001 conquistaron la mayoría de los delegados (12 de 21), y en el 2006 alcanzaron el 90\% de los votos. En estos años la oposición impulsó importantes luchas, que contribuyeron a legitimar el proceso de organización que venía desarrollando. La más reconocida fue la "huelga de los 4 días" durante el año 2004, luego de la que los trabajadores lograron la reducción de la jornada laboral de 8 a 6 horas. Finalmente, en el año 2008 el CD decidió crear un nuevo sindicato: la Asociación Gremial de Trabajadores del Subte y de Premetro (AGTSyP). Los trabajadores ratificaron la decisión mediante un plebiscito donde, con la participación de un $61 \%$ del padrón, el $99 \%$ votó a favor ${ }^{35}$. Luego de conseguir la personería jurídica en el 2010, en 2015 lograron la personería gremial ${ }^{36}$.

En la actualidad, hay tres listas que participan en la disputa por los cargos: (a) La Lista Roja y Negra, que en las elecciones del 2015 obtuvo el 55\% de los votos, conquistando la mayoría de los cargos en la Secretaria Ejecutiva ${ }^{37}$; (b) La Lista Frente de Unidad BordóVioleta, que en las últimas elecciones obtuvo el $27 \%$ de los votos y ocupa actualmente la minoría de la Secretaría Ejecutiva ${ }^{38}$; y (c) La Lista Naranja, que obtuvo en las últimas elecciones el $17 \%$ de los votos ${ }^{39}$. En este sentido, el análisis del caso del Subte es interesante para estudiar cómo se repropia la tradición de izquierda allí donde es disputada por distintas corrientes políticas, que debaten acerca de los sentidos que aquella asume. Por ello, es tan importante distinguir los posicionamientos de cada agrupación en torno a las diferentes dimensiones que abordamos.

Asimismo, la distinción de distintas agrupaciones (todas ellas, como vimos con fuerte presencia de corrientes de izquierda) es también un resultado del propio proceso de organización y lucha del Subte, y representa las diferencias que se fueron gestando al interior del CD entre distintos sectores que reivindicaban la tradición de izquierda. Antes de la creación del sindicato propio, si bien existían enfrentamientos ideológicos entre las distintas agrupaciones, la oposición ante la dirección de la UTA las aglutinaba y permitía la

\footnotetext{
34 Ventrici, op cit.; Colectivo Encuesta Obrera, Experiencias subterráneas. Trabajo, organización gremial e ideas políticas de los trabajadores del subte. Buenos Aires, Ediciones IPS, 2007.

${ }^{35}$ Ventrici, op.cit.

${ }^{36}$ Muy recientemente, en marzo del 2017, este conflicto se reabrió, luego de que la Cámara Nacional de Apelaciones del Trabajo revocara la resolución del Ministerio de Trabajo en la cual se le otorgaba la personería gremial a la AGTSyP.

37 Sus principales referentes son Roberto "Beto" Pianelli y Néstor Segovia, ambos militantes desde los inicios de la organización opositora en el Subte en la agrupación El Túnel. Actualmente, Pianelli es uno de los dirigentes principales de Nuevo Encuentro, y Segovia en 2012 se unió a MILES, la agrupación política liderada por Luis D’Elía.

${ }^{38}$ Sus principales referentes son Claudio Dellacarbonara, militante del PTS, y Ariel Mastandrea, un ex militante de la Lista Roja y Negra que se define políticamente como independiente.

${ }^{39}$ Entre sus principales referentes se destaca Carlos "Charly" Pérez, militante del PO.
} 
Mariela Cambiasso - Julieta Longo - Juliana Tonani, Sindicalismo y tradiciones políticas de izquierda: un estudio cualitativo a partir de tres experiencias del sindicalismo de base en la Argentina durante el kirchnerismo, Izquierdas, 36, noviembre 2017: 126-155

acción conjunta frente a un enemigo en común. Al conformar un sindicato propio, el enfrentamiento con la dirección de la UTA dejó de ser lo que configuraba al escenario político y las diferencias entre las distintas corrientes se profundizaron. En este marco, nos preguntamos ¿qué izquierda se configura hoy en el Subte?

Luego de la creación de la AGTSyP, la oposición a la política de la dirección de la UTA continúa presente, aunque no ostenta la categoría de enemigo principal. Si bien este elemento es central en la orientación política del nuevo sindicato, en tanto es parte de su historia reciente y remite al modo en que se han ido construyendo, ha perdido centralidad en la coyuntura actual para definir las alianzas. La diferencia ya no es entre los Metrodelegados y la dirección de la UTA, sino entre la AGTSyP y los "sindicatos tradicionales":

La esencia de nuestro proyecto de estatuto es que no fuera para nada proscriptivo, y que cualquiera pudiera armar lista y postularse con requisitos mínimos, los requisitos que pide la ley. ¡Tenés cantidades de cláusulas proscriptivas en los estatutos vigentes en otros sindicatos! (Miembro 1 de la Secretaría Ejecutiva, Lista Roja y Negra, militante sindical).

Ahora es como que eso [las asambleas] se va perdiendo, porque ahora el sindicato empieza a tomar decisiones por cuenta propia. No como los sindicatos tradicionales, porque todavía nosotros nos reunimos, tenemos reunión de delegados, donde todavía hay un debate, y aparte, podemos ir nosotros al resto de las líneas, entrar y dar un debate con los compañeros, dejar un volante, que en cualquier otra fábrica eso no pasa. O sea, si hay un lugar donde políticamente hay mucha discusión y hay muchas corrientes que intervienen, que es casi como la facultad, pero nada más que hay trabajadores y no estudiantes, es el Subte (Delegado 1, Lista Naranja, militante partidario y sindical).

La redefinición de los adversarios contribuye a que se intensifiquen las diferencias políticas entre las distintas corrientes que intervienen en el sindicato. Principios que antes eran aglutinadores (como la democracia sindical, la independencia política y la solidaridad con otros sectores de trabajadores) comienzan a entrar en discusión. Se trata de definir ahora, una vez escindidos de la UTA, qué sindicato es necesario construir ${ }^{40}$.

Por ejemplo, una de las discusiones actualmente más importante gira en torno a qué posición tomar frente al gobierno. Si bien en el CD existía consenso acerca de la importancia de defender la independencia política frente al gobierno menemista, con la

\footnotetext{
${ }^{40}$ En este artículo nos enfocamos en las diferencias que pueden observarse entre la actual dirección del nuevo sindicato del Subte (Lista Roja y Negra) y la oposición (Listas Bordó-Violeta y Lista Naranja), dado que entre ellas se observan las diferencias más notorias en términos de los métodos y los objetivos que se proponen.
} 
Mariela Cambiasso - Julieta Longo - Juliana Tonani, Sindicalismo y tradiciones políticas de izquierda: un estudio cualitativo a partir de tres experiencias del sindicalismo de base en la Argentina durante el kirchnerismo, Izquierdas, 36, noviembre 2017: 126-155

asunción del kirchnerismo y la posibilidad de formar un sindicato paralelo, esta cuestión ameritó opiniones disimiles:

Hoy hay muchas diferencias que eran pequeñas en un principio, porque todos reconocíamos los mismos enemigos si se quiere, reconocíamos en el menemismo a un enemigo tremendo, reconocíamos a la empresa como un enemigo tremendo, reconocíamos a la dirección burocrática de la UTA como un enemigo tremendo. (...) Lo que era un frente único de hecho hasta el año 2005, 2006 empezó a tener algunas fisuras por cuestiones políticas sobre todo porque algunos compañeros empezaron a referenciarse en lo que es el kirchnerismo y muchos compañeros empezaron a perder la independencia política que nosotros habíamos planteado que teníamos que tener como organización... (Miembro 1 por la minoría de la Secretaría Ejecutiva, Lista Bordó-Violeta, militante partidario y sindical).

Y una de las cosas que nosotros siempre le criticamos es que Pianelli está esperando que el gobierno le dé la personería gremial (Delegado 1, Lista Naranja, militante partidario y sindical).

De este modo, una singularidad de este caso de estudio se relaciona con la manera en que el nuevo sindicato se distingue y posiciona frente al Estado y a los gobiernos. Aquí no aparece una oposición al Estado como vimos en el caso de Madygraf, sino una diferencia política con algunos gobiernos particulares. Por ejemplo, mientras el Gobierno de la Ciudad de Buenos Aires ${ }^{41}$ se plantea como un otro opuesto a los intereses de los trabajadores, las críticas al Gobierno Nacional ${ }^{42}$ no aparecen tan claras en la voz de los dirigentes oficialistas, y estos posicionamientos, como vimos a partir de las citas, se traducen en diferencias políticas internas al interior del CD y la dirección del sindicato.

Las diferencias internas en torno a la independencia política no sólo definen las oposiciones, sino que también, como veremos más adelante, se ubican en el centro de la configuración de las alianzas. Estas discusiones están habilitadas en el marco de un pluralismo político que se reconoce como una conquista del $\mathrm{CD}$, y como un principio que se sostiene en el nuevo sindicato, que demuestra -afirman tanto los delegados oficialistas como los opositores- un modelo sindical distinto al tradicional. Este pluralismo da lugar a disputar democráticamente la dirección del gremio, lo que puede rastrearse en cada una de las entrevistas donde al mismo tiempo que los delegados ubican al nuevo sindicato "del lado de los trabajadores", evidencian la existencia de diferencias entre las corrientes políticas intervinientes. Por otro lado, sigue en pie la identificación original de la empresa como un adversario:

\footnotetext{
${ }^{41}$ En el momento en que realizamos las entrevistas el Jefe de Gobierno de la Ciudad de Buenos Aires era Mauricio Macri, quien es actualmente el presidente de la Nación.

${ }^{42} \mathrm{Al}$ momento de realizar las entrevistas el cargo de presidente de la Nación estaba en manos de Cristina Fernández de Kirchner.
} 
Mariela Cambiasso - Julieta Longo - Juliana Tonani, Sindicalismo y tradiciones políticas de izquierda: un estudio cualitativo a partir de tres experiencias del sindicalismo de base en la Argentina durante el kirchnerismo, Izquierdas, 36, noviembre 2017: 126-155

La modalidad [de lucha] que vieron ustedes los últimos años también obedeció a que ellos [la empresa] también aprenden...y aprendieron a hacer todo un trabajo de desgaste hacia los laburantes. En cada paro nos meten a los medios, te tiran a los medios por la cabeza, hacen toda una campaña de desgaste. (...) Entonces nosotros también supimos cambiar esto (...) siempre los métodos de la clase obrera deberían variar en función de los medios que uno encuentre. (...) Y eso lo tuvimos que hacer, porque el enemigo también aprendió... (Miembro 2 de la Secretaría Ejecutiva, Lista Roja y Negra, militante sindical)

Pero si la empresa se reconoce como un enemigo y esto contribuye a pensar cómo se conforman las oposiciones y se define el sindicato, no menos importante resultan las discusiones en torno a las solidaridades que se tejen. La relación con otros sectores de trabajadores se reconoce como parte de una historia de lucha que configura el presente de la organización sindical en el Subte. Por tanto, al tiempo que se plantea la solidaridad con otros sectores de trabajadores como parte de la historia reciente de la organización, en la actualidad también se asume la tarea de funcionar como un "ejemplo" para otros colectivos de trabajadores, que indique que es posible luchar y construir un modelo sindical alternativo.

No obstante, aquí se presentan al menos dos tensiones. Por un lado, la responsabilidad de actuar como "ejemplo" y apoyar otras luchas pareciera encontrar un límite en la poca participación de los trabajadores, que termina configurando un desbalance entre lo que la dirección del nuevo sindicato denomina como "la vanguardia activista" y "la base". Y, por otro lado, la imposibilidad de transmitir exitosamente las experiencias de las luchas pasadas a los nuevos trabajadores jóvenes:

Nosotros tenemos una tradición solidaria con nuestros pares, con la clase laburante, desde siempre, desde que somos Metrodelegados, lo cual ciertamente no es una tarea sencilla, a veces no es lo que uno cree. Quizá nosotros, el dirigente, los delegados, estamos a la vanguardia. Ir a la vanguardia es a veces ir en contra de lo que piensa el conjunto de los trabajadores (...) Pero esto lo tengo que decir, porque si no nos estamos mintiendo entre nosotros: esto no es fácil. Si esto lo hubiéramos votado en la asamblea de todos los compañeros [la solidaridad con otros sectores] hubiéramos perdido (Miembro 2 de la Secretaría Ejecutiva, Lista Roja y Negra, militante sindical).

Sobre la base de estas discusiones, la oposición refuerza la importancia de que las decisiones se tomen en asamblea, incluso en aquellos casos donde no está garantizado el acuerdo con la medida que impulsa. Aquí se refuerza el valor de la asamblea como instancia de politización. La asamblea asume en las entrevistas con los delegados de las listas opositoras a la actual dirección de AGTSyP un valor fundamental en términos de la posibilidad de "educar" a las bases, e incentivar su participación en el gremio: 
Mariela Cambiasso - Julieta Longo - Juliana Tonani, Sindicalismo y tradiciones políticas de izquierda: un estudio cualitativo a partir de tres experiencias del sindicalismo de base en la Argentina durante el kirchnerismo, Izquierdas, 36, noviembre 2017: 126-155

Porque de última, aunque sea una acción solidaria, clasista y se la impones por la fuerza, ;tampoco es lo que corresponde! No, no. Termina siendo una decisión de un grupo de gente, aunque sea con la mejor buena voluntad digamos, con el objetivo más altruista que se te pueda ocurrir, pero para los compañeros es algo ajeno, es algo que no discutieron, algo que no pudieron debatir y que tampoco sirve para educarlos (Miembro 1 por la minoría de la Secretaría Ejecutiva, Lista Bordó-Violeta, militante sindical y político).

Hay que superar también otro condicionante antidemocrático: la asamblea es convocada a conveniencia del oficialismo. Anunciada entre gallos y medianoche, de un día para otro, con cero tiempo para prepararla, en un horario al que muchos compañeros no pueden concurrir, con excepción de los que cuenten con permisos o francos, que la directiva tramitará -como ya lo hizo- para sus partidarios (Volante emitido por la Lista Naranja, diciembre de 2014).

Además de las discusiones en torno al lugar que ocupan las asambleas, también existen tensiones en relación a la unidad con otros sectores de trabajadores (solidaridad que trasciende el lugar de trabajo) y la necesidad de responder cotidianamente a las demandas de los trabajadores del Subte:

Estamos todo el día militando y tratando de mejorar los problemas chiquititos, cotidianos de nuestros compañeros, que son muchísimos, muchísimos más de los que se pueden llegar a imaginar. Entonces es también limitado el tiempo que tenés una vez que salís de acá para vivir, y encima hay una impotencia de no poder llegar mucho más que con el ejemplo a veces a otros lugares (...) Yo creo que es una de las deudas que tenemos los trabajadores que estamos mejor, porque el que está en negro o el que lo están echando todos los días tiene que resolver eso primero (Miembro 1 de la Secretaría Ejecutiva, Lista Roja y Negra, militante sindical).

Así, la solidaridad con otros sectores de trabajadores se plantea como una deuda por parte de la actual dirección. Si bien hay luchas concretas de otros sectores donde AGTSyP lleva su apoyo, ya sea declarativamente, con alguna medida de fuerza (como apertura de molinetes) o interviniendo en negociaciones, se trata de un tema que genera discusiones entre las corrientes políticas que intervienen actualmente en el Subte. Para la oposición, la solidaridad debiera ser más extensiva y formar parte de las discusiones con las bases. Por tanto, para este sector la solidaridad no tendría que quedar subsumida a un objetivo inmediato, como puede ser atender las demandas cotidianas del Subte, sino que para ellos la propia tarea del sindicato implica "romper con el corporativismo" para que los trabajadores se sientan todos "parte de una misma clase".

Considerando lo expuesto hasta acá, sostenemos que los rasgos que asume la tradición de izquierda que actualmente se configura en el Subte no pueden explicarse sin tener en 
Mariela Cambiasso - Julieta Longo - Juliana Tonani, Sindicalismo y tradiciones políticas de izquierda: un estudio cualitativo a partir de tres experiencias del sindicalismo de base en la Argentina durante el kirchnerismo, Izquierdas, 36, noviembre 2017: 126-155

cuenta la tensión entre distintas corrientes político-sindicales que históricamente recuperaron dicha tradición política. Tal como vimos, a diferencia de los otros espacios de trabajo analizados, aquí existe una discusión mucho más abierta acerca de qué sindicato construir y eso se expresa en una creciente politización del espacio laboral.

El proceso de institucionalización del nuevo sindicato deja en evidencia que, aun recuperando la tradición de izquierda y reivindicando un mismo pasado de lucha, existen profundas diferencias entre las corrientes políticas que intervienen en el lugar de trabajo. Cuando la dirección de la UTA dejó de ser el enemigo principal, se reforzaron las diferencias internas entre las corrientes, impactando directamente en la definición de sus objetivos. Allí, en la pregunta acerca de qué sindicato se busca construir se destacan dos discusiones principales: la independencia política en relación al Estado y la solidaridad no sólo hacia el interior del lugar de trabajo, sino también con otros trabajadores más allá de las fronteras que impone el espacio laboral. Estas discusiones, que enriquecen la vida sindical, están habilitadas sobre la base del pluralismo político dentro del sindicato, que es señalado como un aspecto positivo por todas las corrientes político-sindicales y que indiscutiblemente distingue al nuevo sindicato del Subte respecto a los sindicatos burocráticos tradicionales.

\section{Reflexiones finales}

En el artículo nos propusimos analizar las características comunes y las heterogeneidades entre tres experiencias sindicales, en las cuales un sector de sus direcciones recupera la tradición política de izquierda: Madygraf, Lear y el Subterráneo de Buenos Aires.

Los tres casos comparten características comunes en torno a los objetivos que se plantean, y también en la manera en que establecen las oposiciones y construyen solidaridades. Concretamente, señalamos que estas experiencias se caracterizan: (a) por entender a la organización sindical como un medio de organización de los trabajadores, (b) por definir las oposiciones en términos de independencia política de la empresa, del sindicato y (con tensiones) del Estado, y (c) por construir solidaridades que trascienden el lugar de trabajo y el sector.

Sin embargo, más allá de los rasgos comunes que comparten estas experiencias, observamos que existen distintos modos en que la tradición de izquierda se materializa en cada una de ellas, incluso a pesar de que en los tres casos se observa una fuerte influencia del trotskismo como corriente política.

A continuación, nos interesa retomar estas discusiones en cada uno de los casos.

En Madygraf, la radicalización del proceso de organización gremial interna se aceleró en los últimos años, luego de que los trabajadores iniciaran la producción bajo gestión obrera, y configuraran a la empresa como un otro prescindible. La radicalización de la que hablamos puede visualizarse a partir de dos ejes principales. En primer lugar, se destaca la centralidad que asume la unidad entre distintos sectores de trabajadores en la política de la organización gremial interna, que no sólo se expresa en el lugar de trabajo (división entre 
Mariela Cambiasso - Julieta Longo - Juliana Tonani, Sindicalismo y tradiciones políticas de izquierda: un estudio cualitativo a partir de tres experiencias del sindicalismo de base en la Argentina durante el kirchnerismo, Izquierdas, 36, noviembre 2017: 126-155

efectivos y contratados, jóvenes y viejos), sino que también atraviesa las fronteras de la fábrica para abarcar a distintos sectores de la clase obrera. Este objetivo, permite que la solidaridad de clase asuma un valor fundamental, tanto a nivel de la dirección de base, como se vio en el caso de Lear, como también se hace extensivo a los trabajadores y activistas. En segundo lugar, se destaca la independencia política, en relación a la dirección del sindicato y al Estado. Este posicionamiento, que ya se planteaba en los momentos de conflicto abierto (por ejemplo, en las negociaciones paritarias), asume un carácter permanente a partir del reclamo por la expropiación de la fábrica. La lucha por la expropiación trasciende la política particular de los gobiernos, cualquiera sea su tinte ideológico, y mantiene abierta la tensión con el Estado, al menos, mientras la demanda no sea alcanzada.

El caso de Lear nos permitió analizar una experiencia de organización de base opositora, en una fábrica relativamente nueva, sin tradición de lucha y de organización, pero en un sector que históricamente atravesó importantes procesos de oposición. Esta situación, así como el carácter aislado de esta experiencia en el gremio (entre 2009 y 2014 la de Lear fue la única CI opositora al SMATA), permite explicar el carácter incipiente y la debilidad de esta experiencia que fue desarticulada tras los despidos masivos de 2014. Al momento de realizar las entrevistas sólo uno de los cinco delegados estaba trabajando dentro de la empresa y la gran mayoría de los activistas habían sido despedidos. Tal como exponemos en el artículo, en este caso observamos que fue el propio conflicto por los despidos de 2014 el que aceleró la configuración de los objetivos de la CI, en vistas a plantear la independencia política de los trabajadores con respecto a la empresa, el sindicato y el Estado. La dirección del sindicato metalmecánico incluso llegó a definirse como un enemigo más importante que la propia empresa. En relación con la solidaridad, la política de la organización de base opositora buscó desarmar las fronteras que dividían a los trabajadores en los espacios laborales. El colectivo de trabajadores se construye entendiendo que las solidaridades se definen a partir de quienes comparten condiciones de trabajo similares $\mathrm{y}$, en algunos casos, esta definición les permite construir vínculos con trabajadores de otras empresas. Pero decimos que este proceso es débil, porque estos elementos no llegaron a consolidarse como características de la CI, sino que fueron surgiendo en respuesta a los despidos de la empresa, a la oposición del sindicato y a las represiones del Estado.

En el caso de Subte observamos dos singularidades que definen los rasgos que asume en la actualidad la tradición de izquierda. Por un lado, es el caso donde se observan mayores continuidades en términos de su historia de oposición y lucha. Por otro, es el único caso donde existen distintas listas que se apropian de elementos de la tradición de izquierda y que debaten qué sindicato es necesario construir. Estas discusiones se exacerbaron en el último tiempo, ya que, como vimos, los principios de independencia política y solidaridad que durante la conformación del CD opositor habían funcionado como aglutinadores de las distintas posiciones, fueron puestos en tensión a partir de la creación de la AGTSyP y los debates que surgieron en torno a esta política. Si bien la independencia política en relación a la empresa sigue operando, lo que se ve trastocado es el posicionamiento en relación a los gobiernos y la centralidad de la oposición frente a la dirección de la UTA como ordenador 
Mariela Cambiasso - Julieta Longo - Juliana Tonani, Sindicalismo y tradiciones políticas de izquierda: un estudio cualitativo a partir de tres experiencias del sindicalismo de base en la Argentina durante el kirchnerismo, Izquierdas, 36, noviembre 2017: 126-155

del escenario político. Con la creación del nuevo sindicato esta diferencia intenta ser repuesta por la oposición al "sindicalismo tradicional". No obstante, esto no es suficiente para reconstruir la unidad lograda entre las distintas corrientes en contra de la UTA, y las diferencias emergen con más fuerza. La institucionalización, a su vez, tiene consecuencias sobre el principio de solidaridad. Mientras que por un lado reivindican la solidaridad de clase, no sólo como un principio a seguir sino como parte de su historia de lucha, por otro lado, encuentran límites en su realización. Estas tensiones se manifiestan en un contexto atravesado por un nuevo interrogante: ¿qué sindicato se quiere construir? De esta manera, la institucionalización presenta el desafío de re-apropiarse del pasado reciente de lucha y organización, al tiempo de disputar la dirección por la construcción del sindicato.

Por otra parte, la disputa entre distintas corrientes políticas de izquierda que se observa en este último caso también permite plantear, para futuros trabajos, nuevos interrogantes centrados no tanto en la comparación de casos, sino en las tensiones que operan al interior de los lugares de trabajo entre distintas corrientes políticas, allí donde las diputas por la tradición de izquierda logran desarrollarse más abiertamente e involucrando al conjunto de los trabajadores.

El estudio de estos tres casos nos permitió dar cuenta de que no existe un único modo en que se recupera una tradición política de izquierda en las organizaciones que se definen en los lugares de trabajo en la actualidad. Por el contrario, podemos afirmar que donde es posible, como en el caso del Subte, incluso existen discusiones acerca de cómo reapropiarse de dicha tradición y legitimar determinadas prácticas y posicionamientos en el płssimenikmo, el análisis comparativo de distintos casos contribuyó a visibilizar que las principales diferencias que pueden observarse no sólo se relacionan con las disputas entre las corrientes políticas que intervienen en los espacios laborales, sino también con las características que asumen las direcciones sindicales, la política empresarial, la historia de lucha y organización del colectivo de trabajadores y el grado de consolidación de estas experiencias opositoras. Estos elementos, que en la historia del movimiento obrero argentino estuvieron atravesados por la tensión entre el peronismo y la izquierda, derivan en la definición de objetivos que plantean posicionamientos diferenciales en torno a la independencia política y la solidaridad de clase. Así, en las distintas experiencias analizadas, fue apareciendo la tensión entre solidaridad y corporativismo, y entre independencia y conciliación. Como resultado de estas combinaciones, es que surgen distintos modos de reapropiarse de las tradiciones, modos que son dinámicos y están en disputa cotidianamente en los lugares de trabajo.

\section{Bibliografía}

Abal Medina, Paula; Arias, Cora Cecilia; Crivelli, Karina y Diana Menéndez, Nicolás. "Las configuraciones del conflicto laboral en empresas de servicios. Un estudio de casos en call centers y 
Mariela Cambiasso - Julieta Longo - Juliana Tonani, Sindicalismo y tradiciones políticas de izquierda: un estudio cualitativo a partir de tres experiencias del sindicalismo de base en la Argentina durante el kirchnerismo, Izquierdas, 36, noviembre 2017: 126-155

Subtes". En: e-l@tina, Revista electrónica de estudios latinoamericanos, vol. 6, n²3, abril-junio. Universidad de Buenos Aires, Facultad de Ciencias Sociales, 2008.

Atzeni, Maurizio y Ghigliani, Pablo. "Nature and limits of trade unions mobilizations in contemporary Argentina", en Labour again publications, Amsterdam, International Institute of Social History, 2008.

Camarero, Hernán. A la conquista de la clase obrera. Los comunistas y el mundo del trabajo en la Argentina, 1920-1935. Buenos Aires, Siglo XXI, 2007.

Cambiasso, Mariela. "Organización sindical en el lugar de trabajo e izquierdas en la Argentina reciente: la Comisión Interna de Kraft-Mondelez (ex Terrabusi)", en: Trabajo y Sociedad, ${ }^{\circ}$ 26: Santiago del Estero, 2016.

Cambiasso, Mariela; Longo, Julieta y Tonani, Juliana. “¿Peronistas? ¿De izquierda? Tensiones en las tradiciones políticas en el sindicalismo de base en la actualidad", en Paula Varela (coord.) $E l$ gigante fragmentado. Sindicatos, trabajadores y política durante el kirchnerismo. Buenos Aires, Final Abierto, 2016.

Ceruso, Diego. La izquierda en la fábrica. La militancia obrera industrial en el lugar de trabajo, 1916-1943, Buenos Aires, Imago Mundi, 2015.

Colectivo Encuesta Obrera. Experiencias subterráneas. Trabajo, organización gremial e ideas políticas de los trabajadores del subte. Buenos Aires, Ediciones IPS, 2007.

Cotarelo, María Cecilia. “Movimiento sindical en argentina 2004-2007: ¿anarquía sindical?”, XI Jornadas Interescuelas - San Miguel de Tucumán, Departamento de historia, Universidad Nacional de Tucumán, 2007.

D’Urso, Lucila y Longo, Julieta. "Sindicalismo y política: el caso de la autopartista Lear como experiencia de sindicalismo radical en Argentina", $12^{\circ}$ Congreso Nacional de Estudios del Trabajo - ASET, Buenos Aires, 2015.

Etchemendy, Sebastian y Collier Ruth. "Golpeados pero de pie: Resurgimiento Sindical y Neocorporativismo Segmentado en Argentina (2003-2007)", en Politics and Society, Vol. 35, No 3, Sage Publications, 2007.

Gilly, Adolfo. "La anomalía argentina (Estado, Corporaciones y trabajadores)", Pablo González Casanova (comp.), El estado en América Latina: teoría y práctica, México DF, Siglo XXI, 2003.

Gindin, Julián. "La tradición sindical y la explicación de las prácticas sindicales. Conclusiones de una comparación internacional sobre los docentes del sector público" en Revista Latinoamericana de Estudos do Trabalho, Ano 16, no 26, 2011.

Giniger, Nuria; Guevara, Sebastián; Hernández, Marcelo y Rivero, Cynthia. "Las huellas del terrorismo de estado sobre el movimiento obrero. Los casos de Ford y Acindar", en Claudia Figari, Paula Lenguita y Juan Montes Cató, El movimiento obrero en disputa, Buenos Aires, Editorial CICUS, 2010.

Hall, Stuart. "Introducción: ¿quién necesita identidad?", en Stuart Hall y Paul du Gay, Cuestiones de identidad cultural, Buenos aires-Madrid, Amorrortu Editores, 2003.

Hobsbawm, Eric. "Tradiciones obreras", en Eric Hobsbawm, Gente poco corriente. Resistencia, rebelión y jazz, Barcelona, Planeta, 2013.

Hobsbawm, Eric. "Introducción: la invención de la tradición", en Eric Hobsbawm (comp.) La invención de la tradición, Barcelona, Editorial Crítica, 2002.

James, Daniel. Resistencia e Integración. El peronismo y la clase trabajadora argentina, Buenos Aires, Siglo XXI, 2006.

Horowicz, Alejandro. Los cuatro peronismos, Buenos Aires, Planeta, 1991. 
Mariela Cambiasso - Julieta Longo - Juliana Tonani, Sindicalismo y tradiciones políticas de izquierda: un estudio cualitativo a partir de tres experiencias del sindicalismo de base en la Argentina durante el kirchnerismo, Izquierdas, 36, noviembre 2017: 126-155

Laufer, Rodolfo. "El clasismo en el SMATA Córdoba. Ocupaciones fabriles, democracia sindical e izquierda clasista: la toma de la matricería Perdriel, mayo de 1970", en Estudios del Trabajo, vol. 49, 2015.

Löbbe, Héctor. La guerrilla fabril. Clase Obrera e izquierda en la Coordinadora de Zona Norte del Gran Buenos Aires (1975-1976), Buenos Aires, Ediciones Razón y Revolución, 2006.

Longo, Julieta. ¿Renovación de las tradiciones sindicales en ámbitos laborales precarizados? Un análisis de las organizaciones sindicales en empresas supermercadistas durante la posconvertibilidad, Buenos Aires, Tesis doctoral, Universidad de Buenos Aires, 201 Hartín, Emilio. "Balance de la lucha de Atlántida", En defensa del marxismo, n 17, julio, 199Vlolinaro, Leandro. "La democracia del Nunca más y el movimiento obrero. La ocupación obrera de la planta Ford de General Pacheco en 1985", en Revista Archivos de Historia del Movimiento Obrero y la Izquierda $\mathrm{n}^{\circ} 2$, Buenos Aires, 2013.

Palomino, Héctor. "La instalación de un nuevo régimen de empleo en Argentina: de la precarización a la regulación" en Revista Latinoamericana de Estudios del Trabajo, Año 13, No 19, 2008.

Pozzi, Pablo y Schneider, Alejandro. Los setentistas. Izquierda y clase obrera. Buenos Aires, Eudeba, 2001.

Schneider, Alejandro. Los compañeros. Trabajadores, Izquierda y peronismo, 1955-1973, Buenos Aires, Imago Mundi, 2005.

Senén González, Cecilia. y Haidar, Julieta. "Los debates acerca de la "revitalización sindical" y su aplicación en el análisis sectorial en Argentina", en Revista Latinoamericana de Estudios

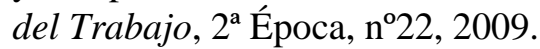

Thompson, Edwards P. La formación de la clase obrera en Inglaterra, Barcelona, Editorial Crítica, 1989.

Thompson, Edwards P. Tradición, revuelta y conciencia de clase. Estudios sobre la crisis de la sociedad preindustrial, Barcelona, Editorial Crítica, 1984.

Torre, Juan Carlos. La vieja guardia sindical y Perón, Buenos Aires, Razón y Revolución, 201łarela, Paula y Vasallo, Débora. "El disciplinamiento en la producción: la estrategia del SMATA en los lugares de trabajo", en Paula Varela (coord.) El gigante fragmentado. Sindicatos, trabajadores y política durante el kirchnerismo, Buenos Aires, Final Abierto, 2016.

Varela, Paula. La disputa por la dignidad obrera. Sindicalismo de base fabril en la zona norte del Conurbano bonaerense 2003-2014, Buenos Aires, Imago Mundi- Colección Archivos, 201 bentrici, Patricia; Vocos, Federico y Compáñez, Manuel. Metrodelegados. Subte, de la privatización al traspaso, Buenos Aires, Editorial Desde el Subte, 2012.

Werner, Ruth y Aguirre, Facundo. Insurgencia obrera en la Argentina 1969-1976. Clasismo, coordinadoras interfabriles y estrategias de la izquierda. Buenos Aires, Ediciones IPS, 2009.

Williams, Raymond. Marxismo y literatura, Barcelona, Editorial Península, 2000.

\section{Documentos consultados y utilizados para el análisis de los casos}

Caso Madygraf

Diarios: Página 12, Clarín, La Izquierda Diario (noticias varias).

Martín, Emilio. "Balance de la lucha de Atlántida", En defensa del marxismo, n 17, julio, 1997.

Caso Lear:

Boletín de Lucha de los trabajadores de Lear ( ${ }^{\circ} 1 \mathrm{a} \mathrm{n}^{\circ}$ 58) [Boletín]

Comunicados de la Comisión Interna [Comunicados] 
Mariela Cambiasso - Julieta Longo - Juliana Tonani, Sindicalismo y tradiciones políticas de izquierda: un estudio cualitativo a partir de tres experiencias del sindicalismo de base en la Argentina durante el kirchnerismo, Izquierdas, 36, noviembre 2017: 126-155

Declaraciones de los trabajadores despedidos y la Comisión Interna de Lear [Declaraciones]

SMATA (30 de mayo 2014) "Los trabajadores mecánicos decimos basta" [Solicitada]

SMATA (9 de agosto 2014) "Los trabajadores mecánicos decimos basta” [Solicitada]

Caso Subte

Página de la AGTSyP: http://www.sindicatodelsubte.com.ar/

Blog de la Agrupación Trabajadores de Metrovías (Lista Naranja): http://atmsubte.blogspot.com.ar/

Facebook Agrupación Democracia desde las Bases (Lista Bordó-Violeta): https://www.facebook.com/democracia.desdelasbases/

\section{Lista de Entrevistados según los casos de estudio}

\begin{tabular}{|c|c|c|}
\hline \multicolumn{3}{|c|}{ Madygraf (ex Donnelley). Sector gráfico. Garín, Escobar. } \\
\hline Año & Posición sindical & Relación con la militancia \\
\hline 2014 & Dirigente & Militante partidario y sindical. \\
\hline 2014 & Activista 1 & Militante sindical. \\
\hline 2014 & Delegado 1 & Militante partidario y sindical \\
\hline 2014 & $\begin{array}{l}\text { Delegada de la Comisión de Riesgos del } \\
\text { Trabajo }\end{array}$ & Militante sindical \\
\hline 2014 & Activista 2 & Militante sindical. \\
\hline \multicolumn{3}{|c|}{ Lear. Sector automotriz. El Talar, Tigre. } \\
\hline Año & Posición sindical & Relación con la militancia \\
\hline \multirow{3}{*}{2014} & Delegado 1 & Militante partidario y sindical, \\
\hline & Delegado 2 & Militante sindical. \\
\hline & Activista 1 & Militante partidario y sindical. \\
\hline 2015 & Delegado 3 & Delegado 3 Lear, sector automotriz. \\
\hline 2015 & Activista 2 & Militante sindical. \\
\hline \multicolumn{3}{|c|}{ Subterráneos de la Ciudad de Buenos Aires. Sector tranviario automotor. CABA. } \\
\hline Año & Posición sindical & Relación con la militancia \\
\hline 2015 & Miembro 1 de la Secretaría Ejecutiva & Militante sindical, Lista Roja y Negra $^{\circ}$ \\
\hline 2015 & Miembro 2 de la Secretaría Ejecutiva & Militante sindical, Lista Roja y Negra ${ }^{\circ}$ \\
\hline 2015 & $\begin{array}{l}\text { Miembro } 1 \text { por la Minoría de la } \\
\text { Secretaría Ejecutiva }\end{array}$ & Militante político y sindical, Lista Bordó-Violeta ${ }^{\circ}$ \\
\hline 2015 & $\begin{array}{l}\text { Miembro } 2 \text { por la Minoría de la } \\
\text { Secretaría Ejecutiva }\end{array}$ & Militante sindical, Lista Bordó-Violeta ${ }^{\circ}$ \\
\hline 2015 & Delegado 1 & Militante político y sindical, Lista Naranja ${ }^{\circ}$ \\
\hline 2015 & Delegado 2 & Militante sindical, Lista Roja y Negra $^{\circ}$ \\
\hline 2015 & Delegado 3 & Militante sindical, Lista Roja y Negra $^{\circ}$ \\
\hline 2015 & Delegado 4 & Militante sindical , Lista Roja y Negra ${ }^{\circ}$ \\
\hline 2015 & Delegado 5 & Militante sindical, Lista Roja y Negra). ${ }^{\circ}$ \\
\hline 2015 & Delegado 6 & Militante sindical, Lista Roja y Negra ${ }^{\circ}$ \\
\hline 2015 & Delegado 7 & Militante sindical, Lista Roja y Negra ${ }^{\circ}$ \\
\hline 2015 & Delegado 8 & Militante sindical Lista Roja y Negra ${ }^{\circ}$ \\
\hline 2015 & Delegado 9 & Militante sindical, Lista Bordó-Violeta ${ }^{\circ}$ \\
\hline
\end{tabular}


Mariela Cambiasso - Julieta Longo - Juliana Tonani, Sindicalismo y tradiciones políticas de izquierda: un estudio cualitativo a partir de tres experiencias del sindicalismo de base en la Argentina durante el kirchnerismo, Izquierdas, 36, noviembre 2017: 126-155 